\title{
SEDIMENT CHARACTERISTICS AND HYDRODYNAMIC SETTING OF REEF PLATFORM SEDIMENTS OF KUNDUCHI, NORTH OF DAR ES SALAAM HARBOUR
}

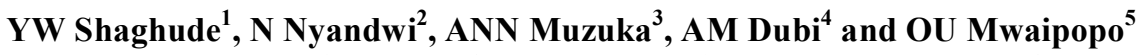 \\ University of Dar es Salaam, Institute of Marine Sciences Zanzibar \\ P.O. Box 668, Zanzibar
}

\begin{abstract}
Sediment grain size distribution, carbonate content and current velocities for the Kunduchi area are used to determine its hydrodynamic setting and sediment characteristics. The sediment mean grain size generally decreases northward. The sediments consist of medium to coarse sand south of the Tegeta River and fine sand further north. The sediment sorting values, which lack a northsouth trend, vary from moderately well sorted to poorly sorted. The skewness of the sediment vary from near-symmetrical to very negatively skewed while the peakedness (kurtosis) varies from platykurtic to leptokurtic. The carbonate content increases with distance offshore, whereas the siliciclastic component decreases with distance offshore. The siliciclastic/carbonate transition of the investigated area is characterized by a narrow transition with no inter-fingering of the two facies. The lack of inter-fingering of the two facies suggests that there is a limited offshore transport of land-derived sediments. This is further supported by the drogue experiment results, which shows that the predominant surface current flows northward irrespective of the tidal phase.
\end{abstract}

\section{INTRODUCTION}

In any shallow water carbonate depositional system, the input of terrigenous sediments to the system is one of the most important limiting factors affecting the carbonate production and its accumulation (Shaghude 2001). Studies in many parts of the world show that as long as the input of terrigenous material is minimal, potential exists for carbonate production and accumulation (Nelson and Bornhold 1983).

Shallow marine carbonate producers, which use seawater to build their skeletons, include autotrophic primary producers (e.g. coralline algae), non-autotrophic benthic sessile organisms (e.g. molluscs, foraminifera, echinoderms and sponges) and sedentary organisms (e.g. corals and bryozoans). The turbidity associated with fluvial discharge of terrigenous sediment can reduce light penetration thereby reducing primary productivity. This would therefore prohibit shallow marine carbonate production by the autotrophic carbonate producers.
Furthermore, as most shallow water benthic and sedentary carbonate producers are suspension feeders, the fine terrigenous materials may clog the body feeding system of these organisms (Carey et al. 1995) and thus inhibit their growth. Also, high input of terrigenous material may bury the benthic carbonate producing organisms and effectively reduce the size of the carbonate system. Apart from fluvial input of suspended matter, erosion of shoreline and nearshore areas owing to high wave climate may contribute a significant amount of silt that may ultimately cause clogging of filter feeders and reduction in light penetration depth. The beach bordering the Msasani Bay is currently experiencing severe beach erosion. Sediments eroded from the beach and those brought from the hinterland through Mbezi and Tegeta rivers are redistributed by tidal currents. Although the work of Muzuka and Shaghude (2000) has indicated a northward transport of beach sediments, the extent of offshore transport of eroded beach material and riverine sediments is not known. Furthermore, the 
Shaghude et al.- Sediment characteristics and hydrodynamic setting ...

impact of sediments to the coastal benthic communities is not known.

Coral reefs, seagrass beds and other coastal ecosystems are important in providing nursery grounds, fishing grounds and protection of shoreline from erosion. Their destruction as a result of siltation may cause collapse of economies of coastal communities. There is therefore, a need of determining the seaward extent of landderived siliciclastic sediment before management decisions can be made.

Current strength is the determinant factor of the particle size transported and sediment distribution pattern in any depositional basin. Coarse sediments require stronger currents than finer sediments. Thus, information on particle size distribution may shed light on variation in energy levels in any deposition basin. In shallow coastal environment tidal, wave and wind generated currents interact in sediment transport. However, at relatively shallow depths the tides may be more important than the waves or currents in the sediment dynamics, but as one goes further offshore the ocean current and the wind generated waves may be more important than the tides.

In nearshore areas, the geomorphic setting of the sea bottom may influence the tidal effects on the coastal area and thus sediment characteristics. Also the physiographic setting influences the major paths of sediment movement and redistribution after their initial deposition. In the case of siliciclastic sediments, these are initially deposited at the river mouths and on beaches. Tidal currents may subsequently transport and re-deposit them further offshore. In indented coasts, where sheltered embayments (bays) are common, the tidal currents may be less effective at transporting sediments within the bays than on those parts which are not sheltered, and such differences may be reflected in the sediment distribution, texture and composition (Barnhardt and Kelly 1995).

The objective of the present study is to determine major sediment characteristics of the Kunduchi area (Kinondoni Coastal Marine Protected Area) in the context of their hydrodynamic setting. The study is expected to shed light on the extent of transport of siliciclastic sediments offshore and possible impact on fringing reefs in the area. This baseline information on sediment characteristics and hydrodynamic condition of the Kunduchi area is useful in the national long-term integrated coastal zone management strategy which, has been developed during the past integrated components from biological and socioeconomic disciplines (e.g. Howell and Semesi 1999; UNEP 2001) but generally lacking information on oceanographic and geological sciences.

\section{MATERIALS AND METHODS Study site}

The investigated area is located approximately $15 \mathrm{~km}$ north of Dar es Salaam Harbour (Fig. 1). It comprises a rectangular coastal strip of about 7 x $15 \mathrm{~km}^{2}$ extending northwards from Mbezi River in the south to Ununio in the north. There are six seasonal rivers in the area. Of the six only the Tegeta and Mbezi are large enough to be considered important with respect to siliciclastic sediment discharge (Fay et al. 1992). The general geology of coastal Tanzania, including the investigated area has been described by Kent et al (1971). The investigated area, like most other lowlying coastal areas of Tanzania is underlain by Neogene non-marine sediments, which are overlain by Mio-Pliocene unconsolidated, poorly sorted gravels, sand, silts and clays. These in turn are overlain by raised reef limestones, beach ridges, sand dunes and superficial white-buff sands of Pleistocene-Holocene age. 


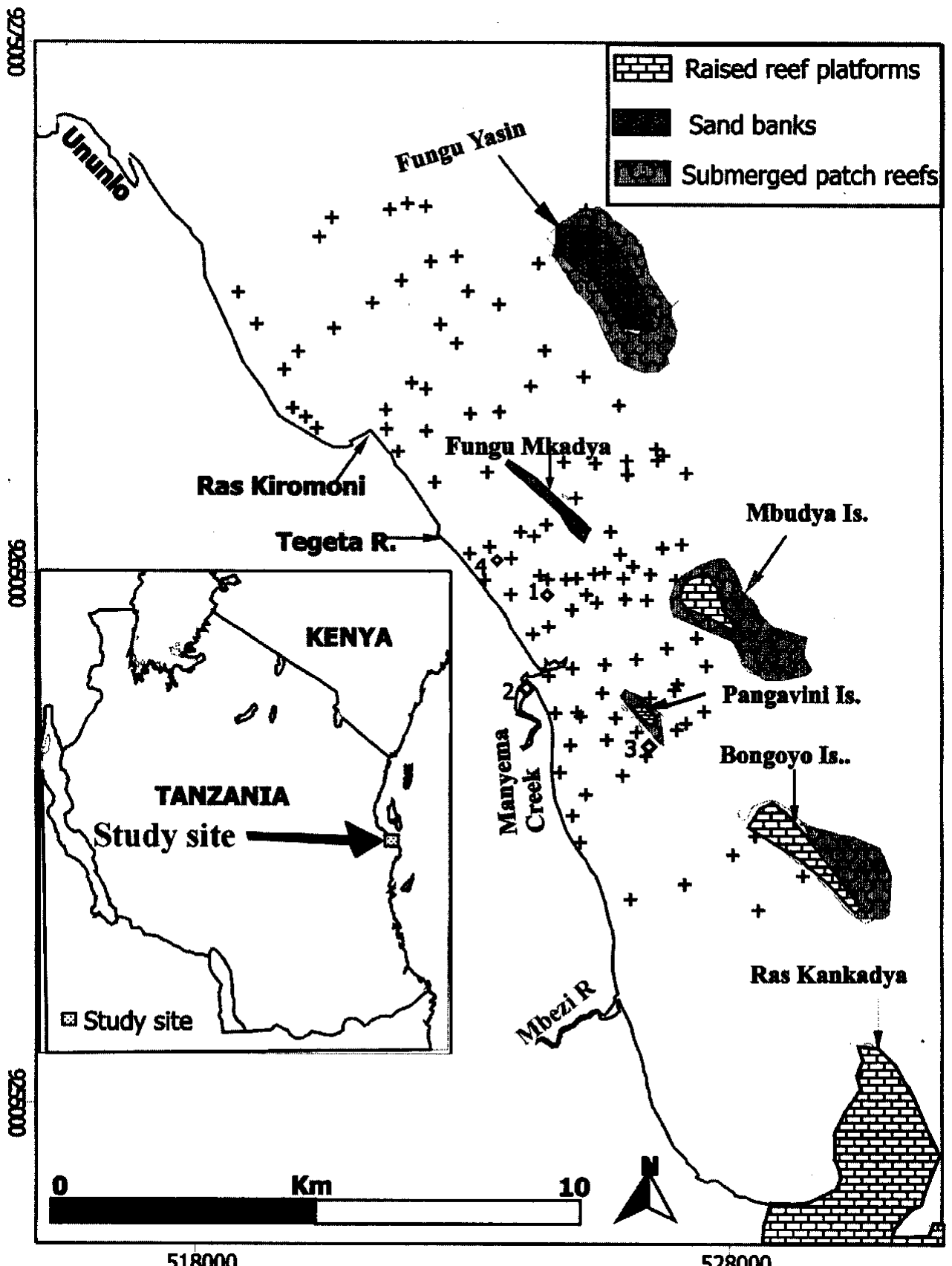

Figure 1: Location map of the investigated area showing the sampling locations (indicated by the small cross symbols) and the locations where the Doppler currentmeter was deployed (the diamond symbols labeled 1 to 4 ). The small cross symbols for the sampling sites are also shown in Figs 2-5. 
Shaghude et al.-Sediment characteristics and hydrodynamic setting ...

Fault movements are considered to play a significant role in shaping the present geomorphological features on the Tanzanian coast (Stockley 1928, Kent et al. 1971, Shaghude and Wannas 2000). Pleistocene and Recent fault lines have divided the coastal plateau into three terraces. The sediments of the investigated area belong to the lowest level, the Mtoni terrace (Alexander 1968). Beach ridge systems are common geomorphological features of this coast and are indicative of Pleistocene/Holocene sea level changes (Alexander 1969, Muzuka et al. 2004). The ridges of the investigated area are elevated by as much as few metres above spring tide level, suggesting that they formed either before a fall of global sea level from a highstand of 1-3 $\mathrm{m}$ above its present position, or as a result of late Holocene uplifting of the Mtoni terrace (Alexander 1969, Fay et al. 1992).

The weather is warm and moist, with annual rainfall exceeding $1000 \mathrm{~mm}$ and sea surface temperature varying between 25 and $30{ }^{0} \mathrm{C}$. Various studies in the investigated area show that both sedimentological and oceanographic phenomena are influenced by the monsoon currents (e.g. Lwiza 1994, Muzuka and Shaghude 2000, Nyandwi 2001). During the northeast monsoon, wind generated waves approach the coast from the northerly sector and upon breaking produce longshore currents with a southerly component. During the southeast monsoon period the wind direction is reversed and so is the wave climate. The speed of the currents is lowest during the northeast monsoon winds (November to March) and highest during the southeast monsoon winds (May to September). As a result of seasonal variability in wave and current conditions, the erosion and accretion of the coastal section north of Dar es Salaam is also cyclic in pattern and intensity. The longshore sediment transport though cyclic has a net northward transport.

\section{Data collection and treatment}

A field campaign was designed for sediment sampling and measurements of currents. Bottom sediment sampling was carried out using a lightweight (approximately $10 \mathrm{~kg}$ ) Van Veen grab sampler at the locations shown in Figure 1. The sampling positions were fixed using a hand held GPS with an accuracy of $\pm 5 \mathrm{~m}$. A total of 112 sediment samples were collected in the investigated area. Current measurements were taken during spring tides at three stations, all located fairly close to the coastline, between water depths of 6 and 8 metres (Figure 1). The instrument used was a self-recording Aanderaa Doppler Currentmeter of the type RCM9, and was positioned $2 \mathrm{~m}$ below the sea surface. Continuous measurements of current speed $(\mathrm{cm} / \mathrm{s})$ and direction were then taken at one-minute intervals, for durations of at least six hours. The spatial behaviour of surface currents was investigated by drogue tracking approach.

All sediment samples were washed with freshwater to remove the salt and then oven dried at $45^{\circ} \mathrm{C}$. The samples were then drysieved to determine granulometric parameters using 12 sieves spaced at $1 / 2$ phi intervals, ranging from -1 phi $(2 \mathrm{~mm})$ to $4 \mathrm{phi}(63 \mu \mathrm{m})$. The grain size distribution parameters (mean, sorting, skewness and kurtosis) were computed according to Folk and Ward (1957). The carbonate content of the samples $\left(\% \mathrm{CaCO}_{3}\right)$ was determined by acid leaching using dilute $\mathrm{HCl}$ acid $(1 \mathrm{M})$ on approximately 3 to $5 \mathrm{~g}$ of a sub-sample; the carbonate percentage in the sample was calculated as weight loss during leaching.

The grain size distribution data (mean grain size, sorting, skewness and kurtosis) and the data on carbonate content $\left(\% \mathrm{CaCO}_{3}\right)$ were used to create appropriate grid files of $\mathrm{XYZ}$ data (where $\mathrm{X}$ and $\mathrm{Y}$ are the geographic coordinates of the measured variable $\mathrm{Z}$ ) for creating contoured maps of the data, using 
Surfer software (Keckler 1995). All the grids were created using kriging option, and contoured.

\section{RESULTS}

The distribution of carbonate content in the sediment, which is expressed as percentage of $\mathrm{CaCO}_{3}$, is presented in Figure 2. The distribution of carbonate content shows two zones, one dominated by siliciclastic sediments $\left(<50 \% \mathrm{CaCO}_{3}\right)$ which is located within a narrow coastal strip, $1-2 \mathrm{~km}$ wide adjacent to the shoreline, and the other dominated by carbonate $\left(>50 \% \quad \mathrm{CaCO}_{3}\right)$ further offshore. The proportion of terrigenous sediments generally decreases gradually from shore to offshore without a sharp break. The sediments close to the raised reef platforms of Bongoyo and Mbudya contain the highest carbonate content $\left(90-100 \% \mathrm{CaCO}_{3}\right)$ and the mode of transition from siliciclastic to carbonate is characterized by a steady increase of the proportion of facies without interfingering of the two facies. The terrigenous coastal strip is widest at the mouths of Mbezi and Tegeta rivers and also north of Ras Kiromoni where the maximum width of dominantly siliciclastic sediments varies from 3 to $4 \mathrm{~km}$ wide.

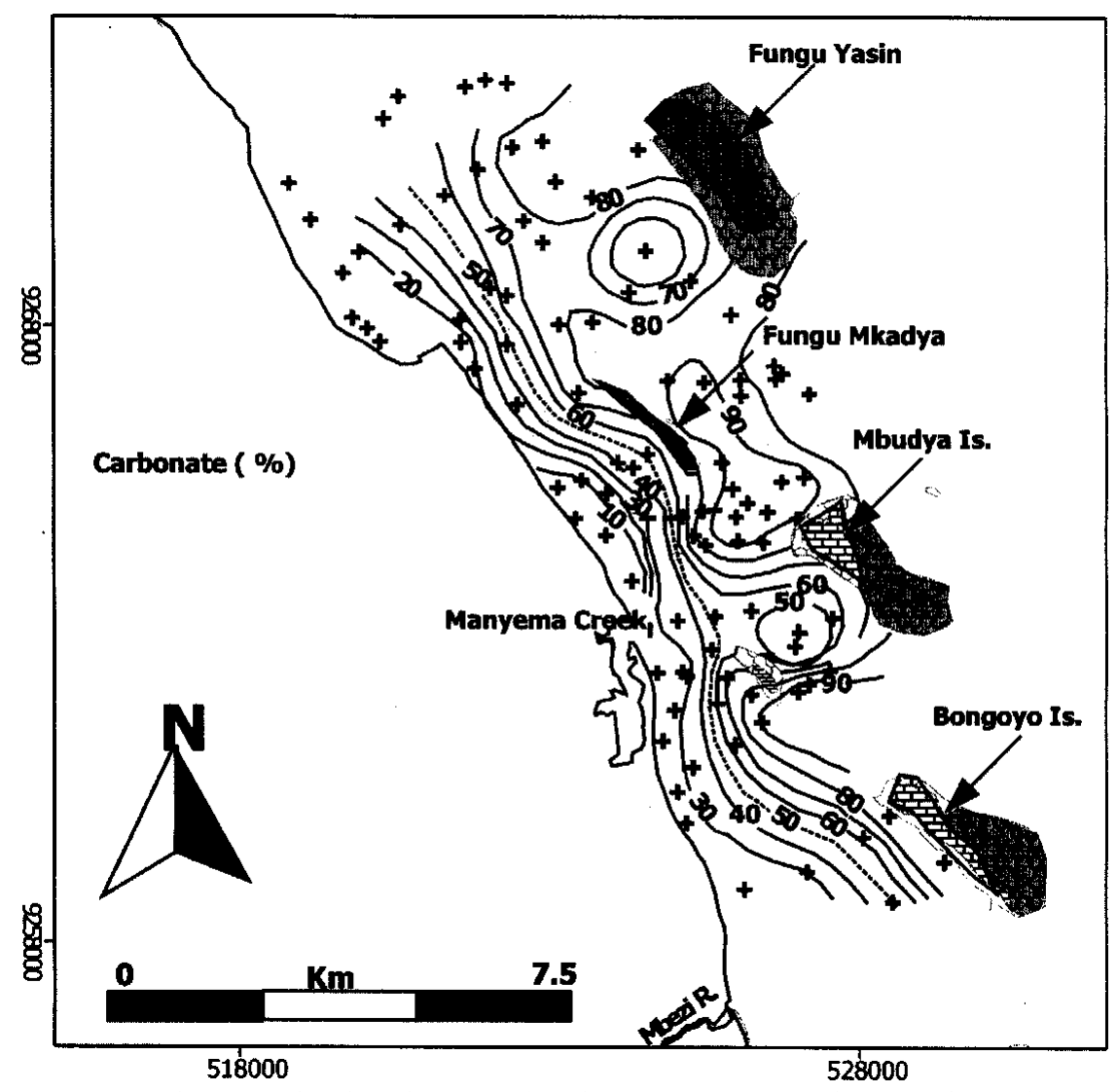

Figure 2: Map showing the distribution of carbonate content in the samples. Observe also the siliciclastic/carbonate transition (the bold dashed line). 


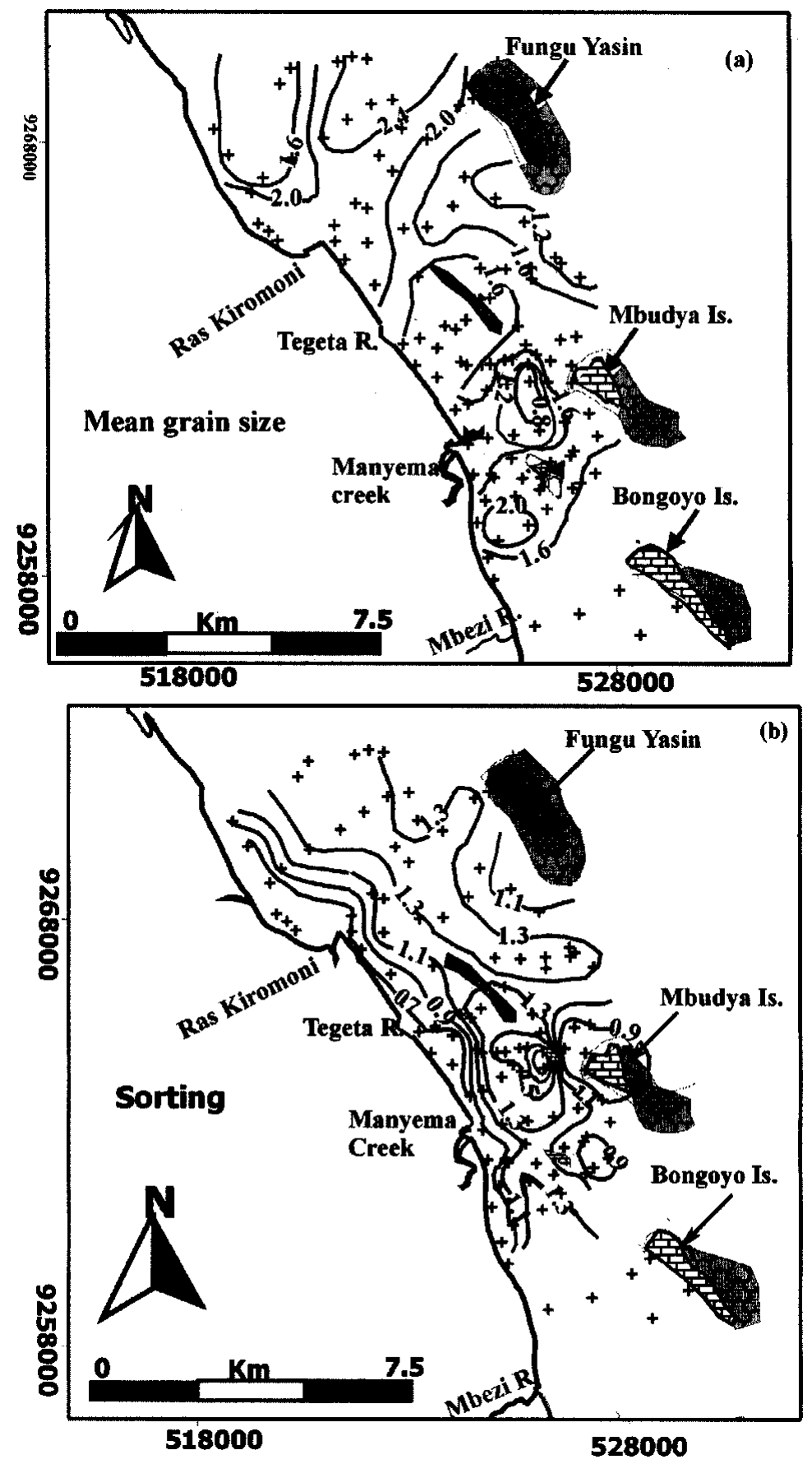

Figure 3: Map showing the distribution of (a) mean grain size and (b) sorting of sediments. 
Trends in mean grain size are less obvious (Fig. 3a). However, when few outliers are excluded, the distribution of mean grain size generally shows a decrease northward with medium coarse sand sediments (1.0 to 2.0 phi) characterizing the sediments south of Tegeta river and fine grained sediments (2.0 to 3.0 phi) north of it. Exceptions to this, include: (i) the medium grain sized sediments between Mbudya, Fungu Mkadya and Fungu Yasin, (ii) the medium grain sized sediments north of Ras Kiromoni.

The sorting of the sediments (Fig. 3b) varies from moderately well sorted $(0.50-$ $0.71)$ to poorly sorted $(1.0-2.0)$. All the sediments collected on the beach were moderately well sorted. Most of the siliciclastic sediments collected further offshore (from the beach) were moderately sorted while most of the biogenic sediments (carbonate rich sediments) were poorly sorted with sorting varying from 1.0 to 1.8 .

The skewness of the sediment (Fig. 4a) varies from near symmetrical $(-0.1$ to +0.1$)$ to very negatively skewed $(<-0.3)$. Generally most of the siliciclastic sediments have near-symmetrical skewness. Most biogenic sediments south of Ras Kiromoni are negatively skewed, while most of the biogenic sediments north of Ras Kiromoni are very negatively skewed.

The peakedness (kurtosis) of the sediments (Fig. 4b) varies from platykurtic $(0.67)$ to leptokurtic (1.11 to 1.50). Platykurtic sediments are limited to two major patches; one in the north and another in the south.
The northern patch is located about half way between the coastline and Fungu Yasin. The southern patch consists of most of the sediments south of Manyema Creek, excluding the beach samples. With the exception Of sediments proximal to Manyema Creek, most of the beach sediments are mesokurtic. The sediments proximal to Manyema Creek and Mbudya patch reef are very leptokurtic.

Maximum current speed measured close to the shore and within the depth of 5 to $8 \mathrm{~m}$ is as high as $40 \mathrm{~cm} / \mathrm{s}$ (Fig. 5-6) whereas within the Manyema Creek it is $66 \mathrm{~cm} / \mathrm{s}$. Peak velocities are higher in the southern area $(35 \mathrm{~cm} / \mathrm{s}$ at Station 3) than in the northern area $(25 \mathrm{~cm} / \mathrm{s}$ at station 4$)$. The current direction indicates a complex pattern with no preferred direction (Fig. 5 $6)$. At stations 1 and 3 the current measurements were taken during flood tide and the current direction is towards northwest at station 1 and towards southwest at station 3 . At station 4 where the measurements were taken during both flood and ebb phases, results indicate that the predominant current direction during flood is towards east and during the ebb phase the current flow predominantly towards west. Inside the Manyema creek, there is no preferred direction of current flow.

Surface current measurement using two drogue experiments (Fig. 7) indicated that the predominant surface current flow is northward irrespective of the tidal phase and the location of deployment. 


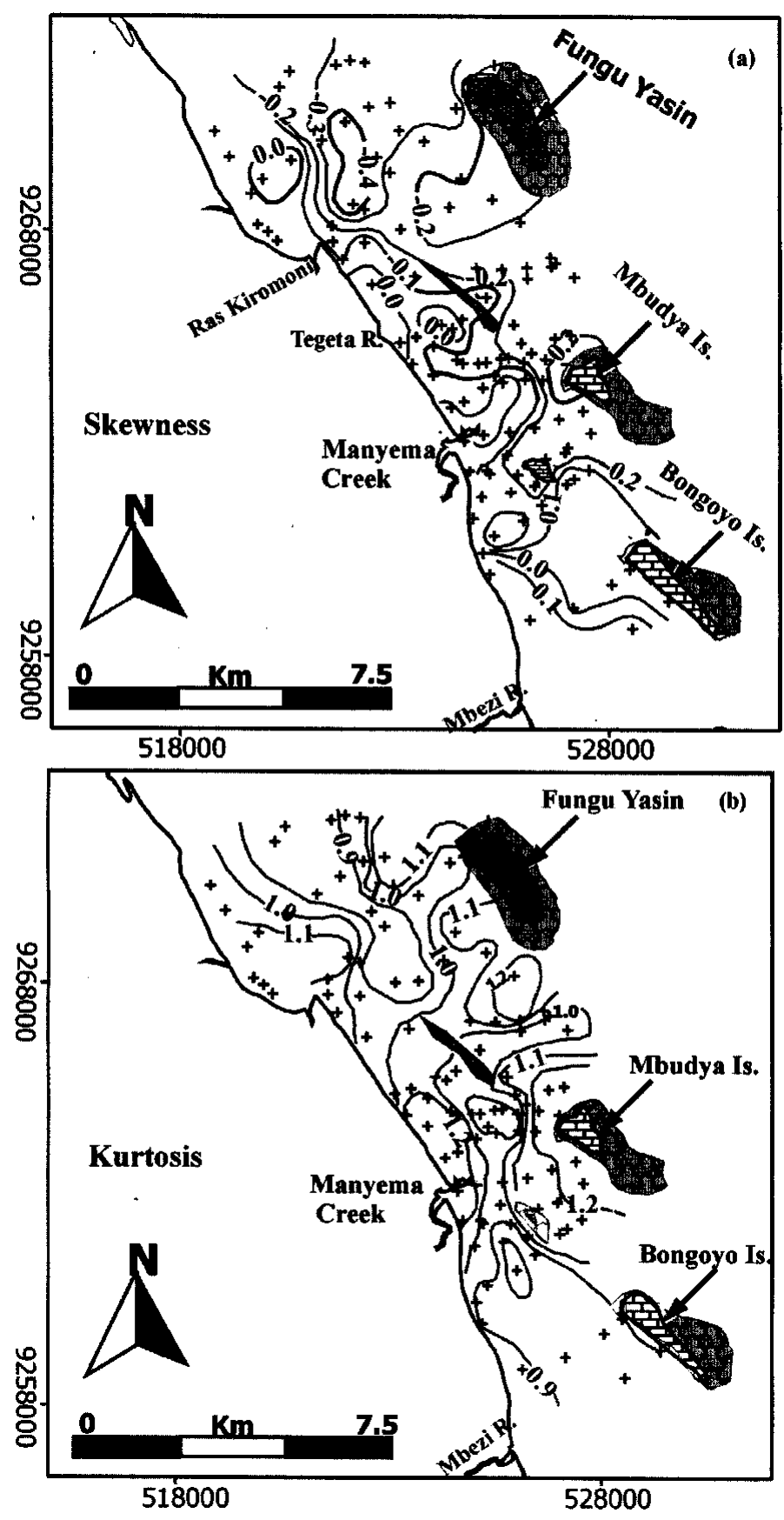

Figure 4: Map showing the distribution of (a) skewness and (b) kurtosis. 

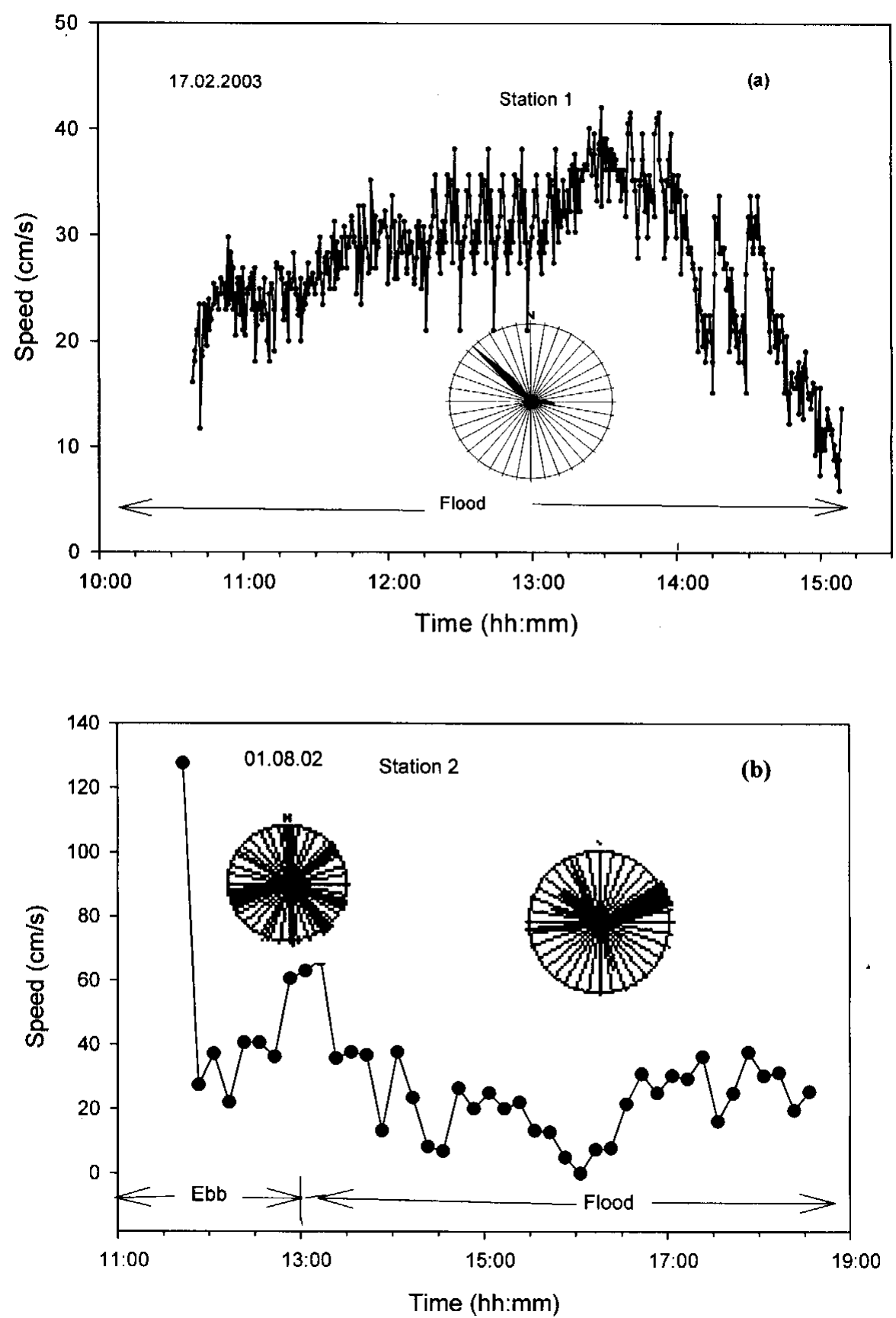

Figure 5: The current speeds at stations 1 and 2 during spring tides. See Fig. 1 for location of the stations. 

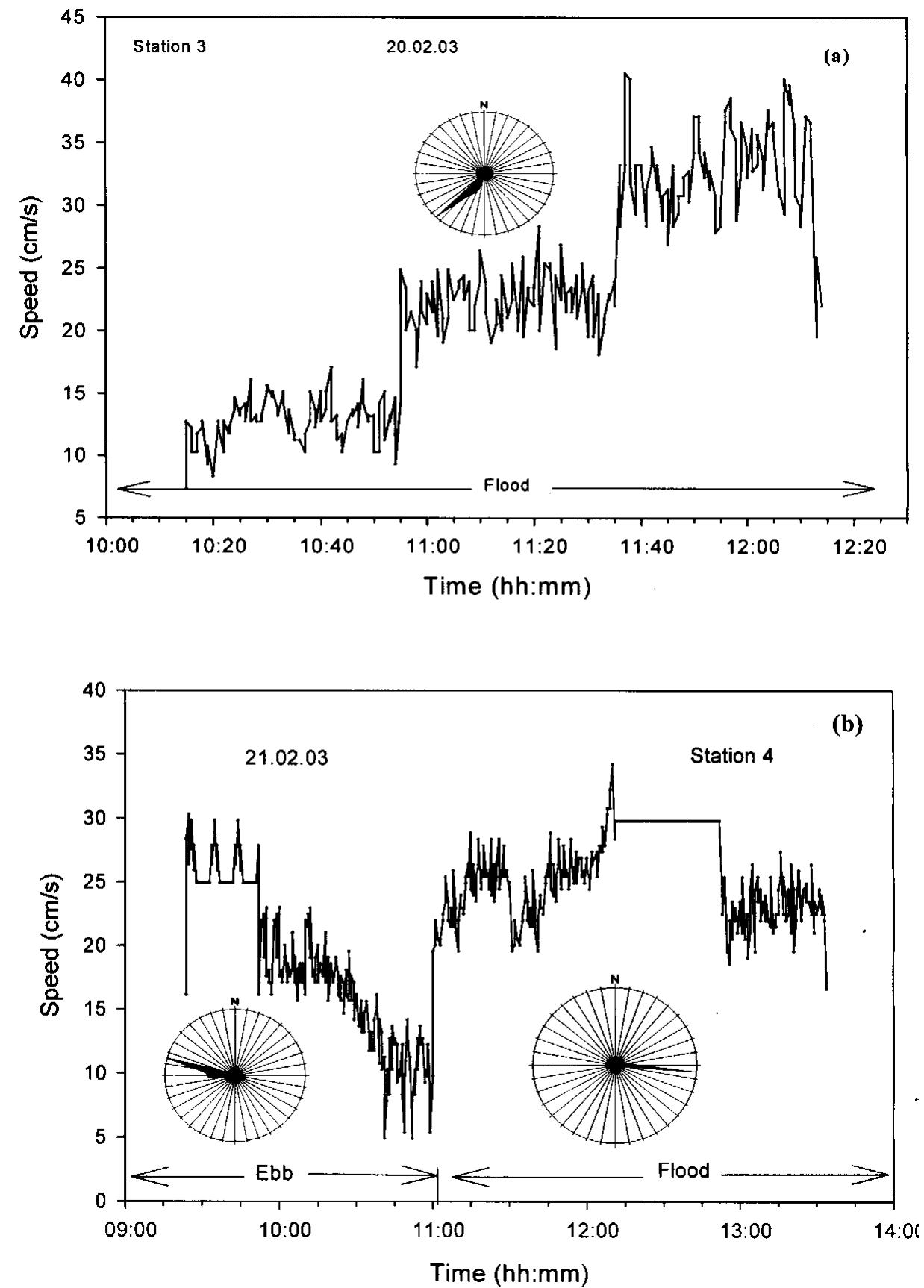

Figure 6: The current speeds at stations 3 and 4 during spring tides. See Fig. 1 for the location of the stations 


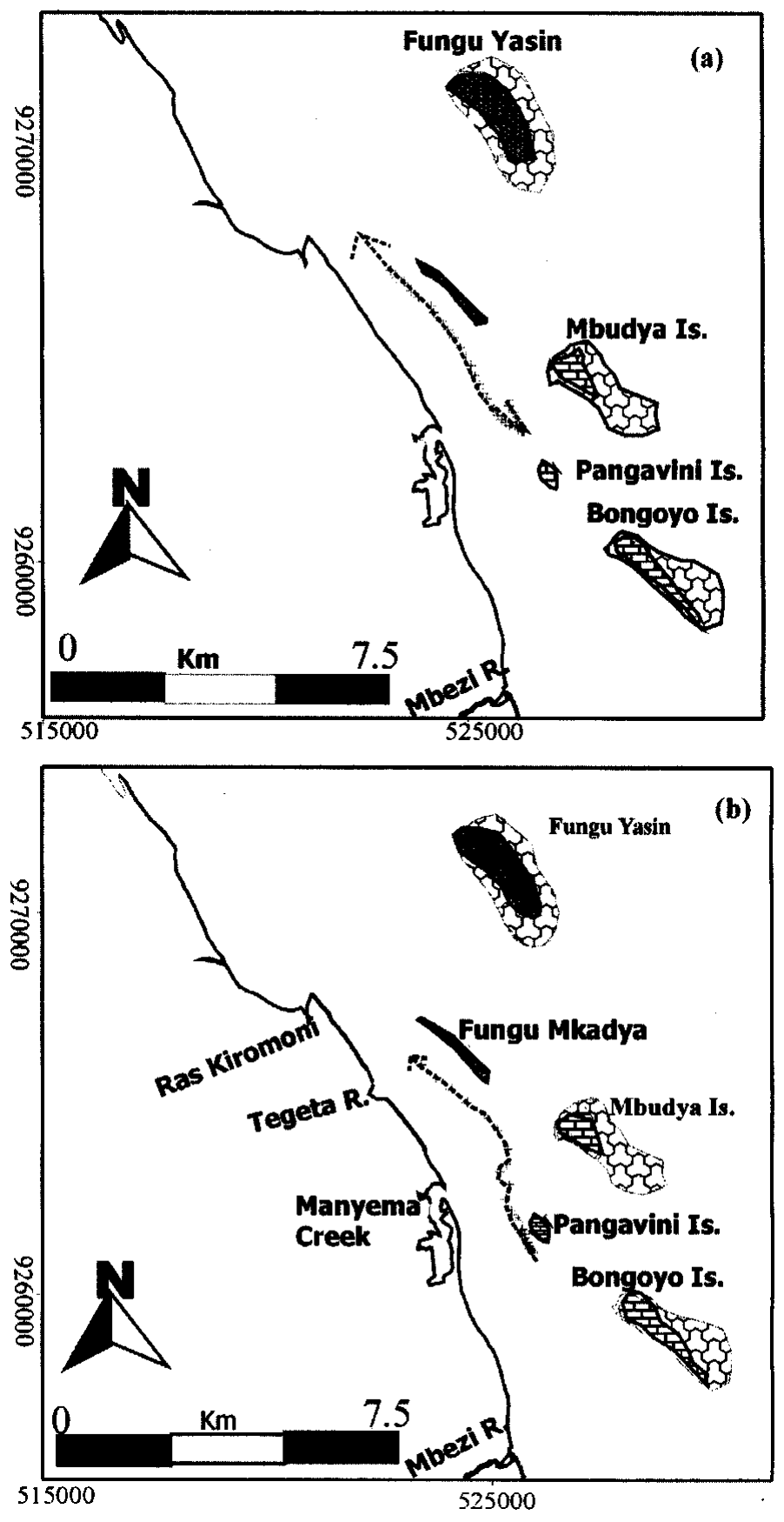

Figure 7: Map showing the surface current flow as demonstrated by the two drogue experiments. 
Shaghude et al.- Sediment characteristics and hydrodynamic setting ...

\section{DISCUSSION}

The distribution of siliciclastic sediments is restricted to a narrow coastal strip between 1 and $2 \mathrm{~km}$ wide adjacent to the shoreline while carbonate dominates beyond this strip with no interfingering between carbonate and siliciclastic facies. This was previously observed in the southern part of the present study area by Fay et al. (1992), and a similar result has been reported off the west coast of Zanzibar (Shaghude 2001, Shaghude et al. 2002). Although a siliciclastic/carbonate transition, which is located closer to the shoreline on the west coast of Unguja Island, was attributed to both the absence of major rivers and the limited occurrence of potential source rocks on the Unguja Island (Shaghude, 2001), the observed narrow siliciclastic/carbonate transition in the Kunduchi sediments can only be attributed to the absence of major rivers (Fay et al. 1992). The sediment contribution by the streams particularly Mbezi and Tegeta rivers, which drain the study area, is relatively low owing to seasonality of flow and moderate to low rainfall that averages $1100 \mathrm{~mm}$ per year (Fay et al. 1992).

The maximum current speed measured at 6 stations in the TDRPS east of the Zanzibar Channel was between 25 to $35 \mathrm{~cm} / \mathrm{s}$ (Shaghude et al, 2002). It is worth noting that, the current measurements reported by Shaghude et al (2002) were taken at depths between 10 and $20 \mathrm{~m}$, with the current meter deployed at a depth of $5 \mathrm{~m}$ above the bottom. Current measurements in the present study were taken at the surface $(2 \mathrm{~m}$ below the surface) at stations located within depths less than $10 \mathrm{~m}(5-8 \mathrm{~m})$. Thus, the current speeds at the two study sites cannot be directly correlated. One would, however, expect the surface currents in the present study area to be higher than the corresponding surface currents in the TDRPS east of the Zanzibar Channel, because the TDRPS are located on the eastern part of the Zanzibar channel, where wind generated waves tend to be minimal because of reduced fetch (Elliot 1986, Brampton 1996).

Although current measurements were taken over a short period, the current flow shows that there is a tidal current coming from the south (Station 3 near Pangavini Island) and another one coming from the east (Station 4) north of Mbudya Island. The two tidal currents probably converge in the vicinity of the Manyema Creek. This, coupled with the ebbjets out of Manyema Creek (Lwiza 1994) could be responsible for the deposition of coarse sediments in the southern part of the study area.

The present study shows that grain size decreases northward. A similar trend was previously observed on the Kunduchi Beach by Muzuka and Shaghude (2000). Current measurements carried out in the present study show that peak velocities are highest in the southern part at station 3 (35 $\mathrm{cm} / \mathrm{s})$ than at station $4(25 \mathrm{~cm} / \mathrm{s})$, probably an indication of a northward moving current. Similarly, the drogue experiments conducted during the present study show that the surface current flow is predominantly northward irrespective of the tidal phase, although this could be a result of wind forcing. Dubi and Nyandwi (2000) found that bottom currents in the intertidal area flooded from the north and ebbed in the reverse direction. Other inferences can be drawn using previous studies on grain size distribution on the beach (Muzuka and Shaghude, 2000) and the distribution of isotopic values of organic carbon in the Msasani Bay (Muzuka 2001). The earlier study (Muzuka and Shaghude 2000) on sediment grain size distribution demonstrated a northward fining associated with improvement in sorting, suggesting that the longshore currents are predominantly northward. Muzuka (2001) reported that the isotopic values of organic carbon in the Msasani Bay (which almost overlaps with the present investigated area) showed a general tendency of increasing northwards. Muzuka (2001) ascribed the 
northward increase of the isotopic values to a northward transport of sediments in the area, which suggests that the bottom currents are assumed to be predominantly northward. Furthermore, the present results on grain size distribution, which are characterized by coarse sediments in the south and fine sediments in the north are also in line with the assumption that the bottom currents are directed northward. The absence of inter-fingering of the siciclastic/carbonate facies, also suggests that there is limited offshore sediment transport of land derived sediments.

Siliciclastic sediments are better sorted than carbonate rich sediments. Similarly siliciclastic sediments are nearly symmetrical skewed and mersokurtic while carbonate rich sediments are generally very negatively skewed and leptokurtic. This could be attributed to high concentration of biogenic remains such as whole shells and shell fragments.

Previous studies sugested that a good percentage of land derived sand material is transported offshore and later brought to the beach at a different location (e.g. Norman 1985, Lwiza 1994). For example, Lwiza (1994) argues that the physical setting of the coastal stretch on the immediate south of Ras Kiromoni, consisting of a cliff with no beach and the seabed adjacent to the shore extensively covered with seagrasses (Syringodium thallasodendron) and the currents at mid tide reaching $0.75 \mathrm{~m} / \mathrm{s}$ would seldom allow direct passage of sand from the south to Ununio Bay. Lwiza (1994) hypothesises that the only possible way for the sand to reach Ununio Bay would be the sand to go offshore first, and then be transported landwards by the wave action, thus bypassing Ras Kiromoni. However, the distribution of $\mathrm{CaCO}_{3}$ on the sea bottom as demonstrated in this study and that of Fay et al. (1992) shows systematic change from terrigenous dominated sediment close to the shore to carbonate dominated sediments further offshore, without inter-fingering of the two facies. The absence of interfingering in the siliciclastic-carbonate transition suggests that there is limited transport of siliciclastic sand offshore. The study of Veland (2005) which used 11 sediment traps distributed at various locations within our study area revealed somewhat similar pattern of results. The sediment traps located proximal to the shore were dominated by siliciclastic sediments, while the sediment traps located proximal to the reefs or further offshore were dominated by carbonate sediments. Thus, our results on carbonate distribution from the sea bottom sediment collected in the study area and the results of the other study by Veland (2005) are in contradiction with the suggestion put forward by Norman (1985) and Lwiza (1994). Therefore, whether the sand at Ununio Bay is deposited after direct transport past Ras Kiromoni from the south (which is unlikely) or after offshore transport and then landward transport by wave action, is subject to debate.

\section{ACKNOWLEDGEMENTS}

Financial support for this study were provided by the Institute of Marine Sciences through Sida-SAREC support. The assistance is gratefully appreciated.

\section{REFERENCES}

Alexander CS 1968 The marine terraces of the northeast coast of Tanzania. Zeitschrift Fur Geomorphologie, Supplement 7: 133-154.

Alexander CS 1969 Beach ridges in northeastern Tanzania. Geographical Review. New York 59: 104-122.

Barnhardt WA and Kelly JT 1995 Carbonate accumulation on the inner continental shelf of Maine: A modern consequence of Quaternary glaciation and sea level change. Journal of Sedimentary Research A65: 195-207.

Brampton A 1996 Processes of beach change, In S.K. Mohammed and J. Betlem (eds). Proceedings of the 
Shaghude et al.- Sediment characteristics and hydrodynamic setting ...

National Workshop on Coastal Erosion Zanzibar, 12 April 1996. Zanzibar Environmental Study Series No. 20.

Carey JS Moslow TF and Barrie JV 1995 Origin and distribution of Holocene temperate carbonates, Hecarte Strait, Western Canada Continental Shelf. Journal of Sedimentary Research A65: 185-194.

Dubi AM. and Nyandwi N 2000 Sediment suspension on a tidal flat near an eroding beach. In $4^{\text {Th }}$ International Conference on Coasts, Ports and Marine Structures, Nov 2000. Shahid Rajaee Port Comlex, Bandar Abbas, Iran, Contribution No. 581, 11pp.

Elliot T 1986 Deltas, In Reading HG (ed). Sedimentary environments and facies. Blackwell Science Ltd. pp. 113-154.

Fay M, Masalu DCP and Muzuka ANN 1992 Siliciclastic-carbonate transition in surface sediments of a back-reef lagoon north of Dar es Salaam, Tanzania. Sedimentary Geology, 78: 49-57.

Folk RL and Ward WC 1957 Brazos river bar: A study in the significance of grain size parameters. Journal of Sedimentary Petrology 27: 3-26

Howell KM and Semesi AK 1999 Coastal resources of Bagamoyo District, Faculty of Science, University of Dar es Salaam, 156p.

Keckler D 1995 Surfer for Windows. Copyright Golden Software Inc. Golden Colorado.

Kent PE Hunt JA and Johnstone DW 1971 The Geology and Geophysics of Coastal Tanzania, 101 p., Geophysical 6, HMS Stationary Office London: Institute of Geophysical Sciences.

Lwiza KMM 1994 Beach erosion north of Dar es Salaam. Proceedings of the IOC-UNEP-WMO-SAREC Workshop on an integrated approach to coastal erosion, Sea Level changes and their impacts. Intergovernmental Oceanographic Commission.
Workshop Report No. 96, Supplement 1:107-111.

Muzuka ANN. 2001 Sources of organic matter in the Msasani Bay and Dar es Salaam harbour. In M.D. Richmond and J. Francis (eds), Marine Sciences Development in Tanzania and Eastern Africa, Proceedings of the $20^{\text {th }}$ Anniversary Conference on Advances in Marine Sciences in Tanzania, 28 June - 1 July 2001, Zanzibar, Tanzania, pp.61-75.

Muzuka ANN and Shaghude YW 2000 Grain size distribution along the Msasani beach, north of Dar es Salaam harbour. Journal of African Earth Sciences, 30(2): 417-426.

Muzuka ANN Nyandwi N and Shaghude YW 2004 Preliminary investigation on the Pleistocene/Holocene sea level changes along the coastline of Tanzania, with reference to Unguja and Pemba islands. Boletim Direcção Nacional de Geologico, Moambique, 43: 8-13.

Norman JO 1985 Project proposal on control of coastal erosion in the recreational area north of Dar es Salaam. Report to the Department of Minerals, Lands, Housing and Urban Development, Dar es Salaam.

Nelson CS and Bornhold BD 1983 Temperate skeletal carbonate sediments on Scott shelf, Northwestern Vancouver Island, Canada. Marine Geology, 52: 241266.

Nyandwi N 2001 Reassessment of the nature of beach erosion north of Dar es Salaam. In M. D. Richmod and Francis, J. (eds), Marine Science Development in Tanzania and East Africa, Proceedings of the $20^{\text {th }}$ Anniversary Conference in Marine Science in Tanzania, pp. 107-120.

Shaghude YW and Wannäs KO 2000 Mineralogical and biogenic composition of Zanzibar channel sediments, Tanzania. Journal of 
Estuarine, Coastal and Shelf Sciences, 51: 477-489.

Shaghude, YW 2001. Shallow water carbonate basin of the Zanzibar channel, Tanzania. PhD Thesis summary, pp. 1-27, Sandlund \& Co Grafiska, Stockholm.

Shaghude YW Wannäs KO and Mahongo SB 2002 Biogenic Assemblage and Hydrodynamic Setting of the Tidally Dominated Reef Platform Sediments of the Zanzibar Channel. Western Indian Ocean Journal of Marine Sciences 1: 107-116.

Stockley GM 1928 The Geology of Zanzibar and Pemba Islands, 44p., Zanzibar: Zanzibar museum.
UNEP 2001 Eastern African Atlas of coastal resources, Tanzania, $111 \mathrm{p}$. UNEP, Nairobi, Kenya.

Veland S 2005 Building houses on sand: Resilience analysis of erosion, sedimentation and coastal management in Msasani bay, Tanzania. MSc Thesis, Department of International Environment and Development Studies, Norwegian University of Life Sciences, 56p., Norway.

http://www.umb.no/noragric/publicati ons/msctheses/Theses-fulltext/2005mnrsa/Veland-Siri.pdf 